\title{
Ticari Gemilerden Kaynaklanan Karbon Emisyonları Üzerine Bir Araştırma ${ }^{1}$
}

\begin{abstract}
Yeşim MİLLET
Yüksek Lisans Öğrencisi, İstanbul Ticaret Üniv., Sosyal Bilimler Ens. Master Student, İstanbul Commerce University, Inst. Of. Social Sci. yesimttoros@gmail.com

Yahya FIDAN orcid.org/0000-0002-5012-3629 Prof. Dr., İstanbul Ticaret Üniversitesi, İşletme Fakültesi Prof. Dr., İstanbul Commerce University, Business Faculty yfidan@ticaret.edu.tr

Nagehan AKOĞLU orcid.org/0000-0001-7438-8640 Dr., İstanbul Ticaret Üniversitesi, İşletme Fakültesi Asst. Prof. Dr., İstanbul Commerce University, Business Faculty candannagehan@gmail.com
\end{abstract}

\section{Öz}

İnsanlık tarihinin başlangıcından itibaren taşıma ve yer değiştirme gerek sosyal gerekse iktisadi anlamda insanların temel ihtiyaçları arasında yerini almıştır. Buluşların ve teknolojinin önlenemez gelişimi insanoğlunun hayat çehresini değiştirdiği gibi doğaya da olumsuz etkiler bırakmaktadır. Endüstri devriminden sonra ülkelerin ve kıtaların kendi aralarında yapmış olduğu taşımacılık faaliyetleri daha da artmıştır. Günümüzde ise lojistik;

\footnotetext{
${ }^{1}$ Bu çalışma Yeşim Millet'in İstanbul Ticaret Üniversitesi Sosyal Bilimler Enstitüsü Lojistik Yönetimi programındaki lisansüstü (YL) tezinden üretilmiştir.
} 
gelişen, değişen ve küreselleşen dünyada artık taşımacılık faaliyetlerinin çok ötesinde birçok faaliyeti bünyesinde barından, önemi giderek artan bir sektör haline gelmiştir. Son yıllarda teknolojinin ve yeni sistemlerin gelişimi ile bazı farkındalıklar ortaya çıkmıştır. Yeraltı kaynaklarının azalması, iklim değişiklikleri, demografik yapılardaki bozukluklar ve rekabet ortamı çevreye olan duyarlılığımızı artırmamızı zorunlu kılmıştır. Çevreye verilen zararın yıkıcı etkilerini nasıl düzeltebileceği ya da asgari düzeye nasıl indirilebileceği hususunda yeni teknik ve teknoloji kullanımının yollarını aramıştır. Bu araştırmada ticari gemilerden kaynaklanan $\mathrm{CO} 2$ emisyonları incelenmektedir. Gemilerden kaynaklanan emisyonların düşürülmesi için Enerji Verimliliği Operasyon Endeksi (EEOI) yöntemi kullanılarak çözüm önerisi oluşturulmuştur.

Anahtar Kelimeler: Lojistik, Sürdürülebilirlik, Deniz Taşımacılığı, Yeşil Lojistik, EEOI

\section{A Study on Carbon Emissions from Merchant Ships}

\section{Abstract}

Since the beginning of human history, transportation and relocation have been among the basic needs of people, both socially and economically. The irrepressible development of inventions and technology not only changes the face of human life, but also leaves irreversible effects on nature. After the industrial revolution, the transportation activities between countries and continents gained even more speed. In recent years, some awareness has emerged with the 
development of technology and new systems. Decrease in underground resources, climate changes and deterioration in demographic structures have made it necessary for us to increase our sensitivity to the environment, and we have sought ways to use new techniques and technologies on how to correct or minimize the destructive effects of damage to the environment. In this research, $\mathrm{CO} 2$ emissions from commercial ships are examined. A solution proposal was created using the EEOI method to reduce emissions from ships.

Keywords: Logistics, Sustainability, Maritime Logistics, Green Logistics, EEOI

\section{Giriş}

Sürdürülebilirlik kavramı yüzyıllardır kullanılan bir kavramdır. Sosyal, ekonomik ve çevresel alanlar gibi birçok alanda kullanıldığı bilinmektedir. Birçok alanda kullanılan bir tanım olmasından kaynaklı olarak kesin bir tanımı bulunmamaktadır. Çoğunluğun kabul ederek kullandığı tanımı World Commission on Environment and Development (WCED), (1987) tarafından yayınlanan “Ortak Geleceğimiz" isimli kitapta bulunan "gelecek kuşakların gereksinimlerine cevap verme yeteneklerini tehlikeye atmadan, günümüz ihtiyaçlarının karşılanması" tanımıdır. Günümüzde sıklıkla çeşitli alanlarda kullanılan sürdürülebilirlik kavramının anlam ve kelime olarak çeşitli tarihsel gelişimlere ve ülkelerin çeşitli çalışmalarına dâhil olduğu görülmektedir.

1960'lı yılların başında Rachel Carson tarafindan yazılmış Sessiz Bahar isimli kitap sürdürülebilirlik konularının önemsenmesinde büyük rol oynamaktadır. Yayınlandığı 30 Haziran 
tarihinden itibaren bir kesimden büyük tepki toplamış olmasına rağmen çevre konusunda farkındalık kazanılmasında önemli yere sahiptir. Rachel Carson Sessiz Bahar isimli kitabını yayınlamadan önce yine farklı kitap denemeleriyle çevresel konulara dikkat çekmeye çalışmıştır. Sessiz Bahar kitabıyla dünyada ses getirmeyi başarmıştır. Biyolojik çeşitliliğin yok edilmesi, her türlü çevresel kirlilik gibi birçok günümüz konularına ilk defa bu kitap ile dikkat çekilmektedir (Özdă̆, 2011). Sürdürülebilirlik konusuna dikkat çekildikten sonraki dönemlerde çevreye verilen zararların geri dönülemez boyutlara ulaştığı görülmüştür ve dünyada bazı önlemler alınması adına adımlar atılmıştır. Bozloğan, (2005) 1972 yılında Stockholm Konferansı, 1987 yılında Ortak Geleceğimiz Raporu, 1992 yılında Rio Zirvesi, 1996 yılında Habitat 2 Zirvesi, 1997 yılında Rio + 5 Zirvesi, 2002 yılında Johannesburg Zirvesi yapılarak; çevresel konularda önlemler alınabilmesi için uluslararası çalışmalar yapılmıştır.

Denizyolu taşımacılığı, tek seferde taşınabilen malzemenin boyutu, diğer taşımacılık türlerine göre daha uygun maliyetlerle taşınabilmesi gibi pek çok sebeple günümüzde dünyada en çok tercih edilen taşımacılık türü haline gelmektedir. Dünya genelindeki ticari faaliyetlerin taşımacılığının \%90'ı denizyolu taşımacılığıyla yapılmaktadır. Denizyolu taşımacılığı; karayolu ve havayolu taşımacılık modlarına karşın daha çevreci olarak bilinse dahi, taşımacılık sıklığı da göz önünde bulundurularak çevresel olarak oldukça olumsuz etki oluşturabilmektedir. Hava kirliliği, su kirliliği ve denizlerdeki gemi yoğunluğu gibi çevresel olumsuz etkiler açı̆̆a çıkmaktadır. Denizlerde, okyanuslarda veya iç su yollarında açığa çıkan olumsuz etkiler sadece o bölgeleri değil aynı zamanda karasal 
bölgeleri de açı̆̆a çıkan hava kirliliğiyle etkilemektedir (Mitraa, Choudhury, Sengupta ve Agrawal, 2019). Avrupa Birliği gemilerin çevreye vermekte olduğu zararları incelemekte ve eğer önlemler arttırılmazsa 2050 yılına kadar emisyon oranlarının \%50 ile \%250 oranında artacağını öngörmektedir. Düşük emisyon oranlarının sağlanabilmesi için ise denizcilik sektöründe ayak izi oluşturmayan yeni teknolojilerin kısa süre içerisinde kullanılmasının gerekliliği belirtilmektedir (Eurostat Statics Explained, 2020). Dünya ticaretinde önemli bir yere sahip olan denizyolu taşımacılığının birim taşıma başına düşen emisyon oranı düşük olsa dahi çevreye ciddi boyutlarda zarar vermektedir.

Zararlı gazların açığa çıkması sera etkisi ve küresel ısınma gibi çevresel etkilere sebep olmaktadır. Sera etkisi; zararlı gazların atmosferde yansıyan güneş ışınlarını tutması sebebiyle dünyanın olması gerekenden daha fazla ısınması anlamına gelmektedir. Dünyanın atmosferden gelen ışınlardan daha çok yansıyan ışınlardan ısındığı bilinmektedir. Sera etkisinin bir sonucu ise küresel ısınmadır. Küresel ısınma bir diğer adıyla iklim değişikliği olarak da bilinmektedir. İklim değişikliği; karbondioksit gibi zararlı gazların atmosferde tutunması sebebiyle ışınların atmosfer dışına aktarılamaması sebebiyle oluşmaktadır (Aksay, Ketenoğlu ve Kurt, 2005). Uluslararası Denizcilik Kurumu (International Maritime Organization, (IMO), çevreye verilen zararların en aza indirgenebilmesi için Birleşmiş Milletler Sürdürülebilir Kalkınma Hedefi stratejilerini desteklemekte ve bu doğrultuda uluslararası denizcilikte çevreye verilen zararların azaltılabilmesi için ortak stratejik amaca hizmet ettiğini açıklamaktadır. IMO, çevrecilik 
hedeflerinde Paris Anlaşması hedeflerini de dikkate alarak, 2008 yılından 2030 yılına kadar emisyonlarda minimum düzeyde $\% 40$ azalma, bu hedeften 20 yıl sonra da yine minimum düzeyde \%70 oranında azalma hedeflemektedir. Bu hedefin gerçekleştirilebilmesi için belirledikleri strateji ise; devletlere, işletmelere çevre, yeni teknolojiler, düşük emisyon gibi konularla ilgili eğitim verilmesi ve bilinç oluşmasının sağlanabilmesidir.

Gemilerin ortalama 30 yıl, bakım, yenileme ve tamir yapılarak ise en fazla 50 sene ömrü olduğu bilinmektedir. Eski gemilerde kullanılan teknolojinin geri kalmış olması, enerji verimliliğin yeterince sağlanamaması ve kullanılan yakıt türünün çevreye zararlı olması sebebiyle daha fazla CO2 emisyonuna sebep olmaktadır (European Commission, 2020). Gemilerde kullanılan yakıtlar zararlı gazların açığa çıkmasına neden olmaktadır. Bu yakıtlar geminin seyri ve gemideki 1sınma, elektrik ihtiyacı, gemi için makinelerin çalıştırılabilmesi gibi durumlarda kullanılmaktadır. Gemilerde sıvı yakıt, katı yakıt ve gaz yakıt kullanılabilmektedir. Geminin büyüklüğü, yük ve yolcu taşıma kapasitesi, seyir hızı gibi birçok etken gemide kullanılacak yakıt türüne karar vermede etkendir. Büyük hacimli gemiler küçük hacimli gemilere nazaran daha fazla enerji tüketimine ihtiyaç duyduğu için kullanılan yakıt türü küçük hacimli gemilere göre daha ağırdır (Durmaz, 2015). Denizyolu taşımacılığından kaynaklanan emisyonlar ise; karbondioksit (CO2), azot oksitler (NOx), Sülfür oksitler (SOx), Partikül madde (PM), hidrokarbon (HC), Karbon monoksit (CO) olarak siralanabilmektedir (Şenol, 2020). 2020 yılında yayınlanan European Commission, (2020) raporuna göre; denizyolu taşımacılığında 40 milyon tondan daha fazla 
yakıt tüketilmiştir. Bu yakıtların yarısından fazlası ağır kirletici yakıtlardan oluşmaktadır. Konteyner gemileri toplam CO2 salınımının \%30'unu oluşturmaktadır. Rapor oluşturulurken dünya filosundan izleme gemileri seçilmekte ve konteyner gemileri bu gemiler arasında izlenen taşıma kapasitesinin \%20'lik diliminden daha az bir dilimi temsil etmektedir. İzlenen konteyner gemileri toplamda 70.000 milyon tondan daha fazla ölü ağırlığı (DTW) bulunmaktadır. Ortalama hızları 14 deniz mili (knot) olarak bilinmektedir. CO2 salınımının \%13'ünü ise dökme yük gemileri oluşturmaktadır. Bu gemiler izlenen taşıma kapasitesinin neredeyse $\% 40$ 'ını oluşturmaktadır. Ortalama hızları ise konteyner gemilerinden daha düşüktür. 10.5 knot ortalama hızları bulunmaktadır.

\section{Literatür Taraması}

Denizyolu taşımacılığında gemiler, limanlar ve liman içi kullanılan araçlar; deniz, hava ve çevresel kirliliğe neden olabilmektedir. Denizlerin kirletilmesi konusunda Özdemir (2012) makalesinde; deniz kirliliğini iki ana başlık altında incelemektedir. Denizlerin gemiler tarafından kirletilmesinin yanı sıra karasal etkenler daha büyük oranda zarar vermektedir. Gemiler sebebiyle oluşan kirlilikler incelendiğinde ise; gemilerin faaliyetlerine devam ederken verdiği zararın yanı sıra oluşan gemi kazaları da denizlerin kirletilmesine sebebiyet vermektedir. Gemilerin faaliyetleri sırasında çeşitli atıkların denizlere atılması, gemilerin sebep olduğu deniz kirliliğinin başlıca nedeni arasında yer almaktadır. Denizyolu taşımacılığı sebebiyle oluşan hava kirliliği konusunda Aygül ve Baştuğ (2020) yaptıkları araştırmalarında özellikle gemilerde kullanılan 
makinelerin çalıştırılabilmesi için kullanılan fosil yakıtların açığa çıarttığ1 emisyonlara değinmektedirler. NO2, CO2, $\mathrm{CO}$ gibi salınımlara sebep olarak çevreye, doğaya, insan yaşamına doğrudan zarar veren fosil yakıtların kullanım sıklığı oldukça fazladır. Bu kullanım sıklığı, küresel ısınmaya, ozon tabakasının delinmesine, kanser gibi birçok hastalığa sebep olmaktadır. Emisyonların azaltılması hayati derecede önem taşımaktadır. Azaltılabilmesi için; uluslararası çerçevede kuralların belirlenip takip ve kontrol edilmesi gerektiğine dikkat çekmektedir. Denizlerin gemiler sebebiyle kirletilmesinin diğer nedenleri incelendiğinde ise Küçük ve Topçu (2012) yapmış oldukları araştırmalarında özellikle tehlikeli madde taşımacılığında genellikle insandan kaynaklanan hatalar sebebiyle etiketlemenin yanlış yapılması, tehlikeli maddenin yönetmelik dışında yanlış bir şekilde yüklemesinin gerçekleştirilmesi gibi durumların da kirliliğe yol açtı̆̆ına değinmektedir.

Denizyolu taşımacılığı dünya ticaretinin en çok yapıldığı taşımacılık türüdür. Lister (2014) araştırmasında bu denli tercih edilen ve ekonomik fayda sağlayan taşımacılık türünün çevreye verdiği zararın azaltılabilmesi için kamu ve özel sektörün birlikte hareket etmesinin gerekliliğine değinmektedir. İşletmelerin yaptıkları çalışmaların ötesinde uluslararası örgütlerin çalışmalarını genişleterek tek düze bir sistem geliştirmelerinin gerekliliğine değinmektedir.

Mitraa, Choudhury, Sengupta ve Agrawal çalışmalarında denizyolu taşımacılığının potansiyeli ve gelişimiyle ilgili yapmış oldukları çalışmalarında gemilerden kaynaklanan emisyonları inceleyerek çözüm önerilerini değerlendirmektedirler. Denizcilik faaliyetleri devam ederken enerji sürdürülebilirliği 
konusunda değerlendirmeler yapılan araştırmada; Hindistan'da denizcilik sektöründe büyüme görülebilmesi için yeşil çözümlerin de kullanılmasının gerekliliğine değinmektedir.

Psaraftis (2016) denizyolu taşımacılığında yeşil çözümler geliştirilirken ekonomik kriterlerin geri plana atılmaması gerekliliğine dikkat çekmektedir. Yapılan çalışmada "kazan-kazan" yöntemi tartışılmakta ve bu yöntem doğrultusunda çevresel faktörlere hız düşürme gibi çözüm yöntemleri geliştirilirken ekonomik faktörlerin dikkate alınmadığı sonucuna ulaşılmıştır. Bu doğrultuda işletmeler ekonomik faktörleri tercih edeceğinden çevresel çözümlere yeterince önem verilmeyecektir. Kazan- kazan yönteminde ise çevresel fayda sağlanırken aynı doğrultuda ekonomik faydanın da sağlanmasının gerektiği tarşılmaktadır.

\section{Araştırmanın Yöntemi}

Araştırmada kullanılan EEOI (Energy Efficiency Operational Indicator) yöntemi IMO'nun uluslararası olarak yayınladığı, hala çalışmaya devam eden gemilerin enerji verimliliğinin matematiksel olarak hesaplanmasına yardımcı olan bir yöntemdir. EEOI gönüllü olarak kullanılan bir yöntemdir. Gönüllü olarak kullanılabilmesi için formülü MEPC.1/Circ.684 ile Ağustos 2009'da kullanıma açılmıştır. Temel amaç; gemilerdeki enerji verimliliğinin arttırılması için matematiksel verilere dayanan hesaplamaların yapılmasına kılavuz görevi görmesidir ve taşıma sırasında yayılan CO2 miktarının çeşitli yöntemlerle düşürülmesini sağlamaktır. Kullanılan yöntem taşıma işi yapan bütün gemiler için kullanılabilmektedir (Internatıonal Marıtıme Organization, 2009). 


$$
\begin{gathered}
\text { EEOI }=\frac{\text { Gerçekleşen } \mathrm{CO}_{2} \text { Emisyonu }}{\text { Gerçekleşen taşıma işi }} \\
\text { EEOI }=\frac{\sum_{\mathbf{j}} \mathrm{FC}_{\mathbf{j}} \times \mathrm{C}_{\text {Carbon }}}{\sum_{\mathbf{j}} \mathrm{m}_{\mathrm{Cargo}_{\mathbf{j}}} \times \mathrm{Dj}}
\end{gathered}
$$

$\mathbf{F C}_{\mathbf{j}}$; Sefer sırasında kullanılan yakıt tüketim miktarı

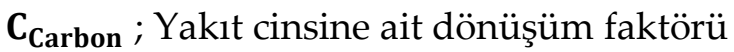

$\mathbf{m}_{\text {Cargo }_{\mathbf{j}}}$; Taşınan yükün kütlesi (ton, yolcu veya TEU)

Dj ; Sefer mesafesi (mil cinsinden)

$\mathbf{F C}_{\mathbf{j}}$ Değerinin hesaplanabilmesi için yakıt tüketiminin bilinmesi gerekmektedir. $\mathbf{F C}_{\mathbf{j}}=\mathrm{Kw}^{*} \mathrm{SFC}$ (Specific Fuel Consumption) formülü kullanılarak hesaplanmaktadır.

$$
\text { C Carbon Hesaplanmalarında (International Marıtıme }
$$
Organızation, 2009) yayınlanan Tablo 1'de bulunan verilerden yararlanılmaktadir. 
Tablo 1. Yakıt Cinsine Ait Dönüşüm Faktörleri

\begin{tabular}{|c|c|c|c|}
\hline Yakıt Cinsi & Referans & $\begin{array}{l}\text { Karbon } \\
\text { Niceliği }\end{array}$ & $\begin{array}{l}\mathrm{C}_{\mathrm{F}}\left(\mathrm{t}-\mathrm{CO}_{2} / \mathrm{t}-\right. \\
\text { Fuel })\end{array}$ \\
\hline Diesel/Gas Oil & $\begin{array}{l}\text { ISO } 8217 \text { Grades DMX } \\
\text { through DMC }\end{array}$ & 0.875 & 3.206000 \\
\hline Light Fuel Oil (LFO) & $\begin{array}{l}\text { ISO } 8217 \text { Grades RMA } \\
\text { through RMD }\end{array}$ & 0.86 & 3.151040 \\
\hline Heavy Fuel Oil (HFO) & $\begin{array}{l}\text { ISO } 8217 \text { Grades RME } \\
\text { through RMK }\end{array}$ & 0.85 & 3.114400 \\
\hline Liquified Petroleum & Propane & 0.819 & 3.000000 \\
\hline Gas (LPG) & Butane & 0.827 & 3.030000 \\
\hline $\begin{array}{l}\text { Liquified Natural Gas } \\
\text { (LNG) }\end{array}$ & & 0.75 & 2.750000 \\
\hline
\end{tabular}

Kaynak. (Internatıonal Marıtıme Organızatıon, 2009).

Araştırmanın evreni 01.09.2021 ve 30.09.2021 tarihleri arasında Atlas Okyanusunda, Hint Okyanusunda ve Büyük Okyanusta seferde olan, Heavy Fuel Oil (HFO) yakıt kullanan Ro-Ro, dökme yük ve kargo gemileridir. Bu kapsamda örneklem oluşturmak için rassal olarak 30 adet gemi seçilmiş ve çalışma onlar üzerinden gerçekleştirilmiştir. $\mathrm{Bu}$ gemilerden 20'si Atlas Okyanusunda, 3'ü Hint Okyanusunda, 7'si Büyük Okyanusta seferde olan gemilerdir. Bu 30 geminin sadece bir seferi seçilerek $\mathrm{CO} 2$ salınımı hesaplanmıştır. Seçilen gemiler yük taşımacılığı yapan ticari gemilerdir, diğer gemiler araştırmanın kapsamına alınmamıştır. Gemilerin yakıt türlerinden HFO değerlendirmeye alınmıştır, Tablo 1'de bulunan diğer gemi yakıtları hesaplanmamıştır. Gemiler stabilize için tam motor kapasitesi kullanımı tercih edebilmektedir. Hesaplamalarda gemilerin maksimum kapasite ile çalıştığ 1 varsayılarak hesaplamalar yapılmıştır. $\mathrm{Bu}$ araştırmada gemilerin motor kapasitelerinin düşük güçte çalıştırıldığı durum hesaplanarak stabilizeleri hesaba katılmamıştır. 


\section{Bulgular}

Gemilerin tam kapasiteyle çalışmaları durumda CO2 salınımları Tablo 2'de incelenmektedir.

Tablo 2. Kapasitenin \%100 Olması Durumunda

\begin{tabular}{|c|c|c|c|c|c|}
\hline GEMİ & $\mathrm{FCJ}$ & CCARBON & MCARGO & DJ & GCO2/T.MILES \\
\hline GEMİ 1 & 4327182 & 3,1144 & 25661,25 & 1750 & 0,225073806 \\
\hline GEMİ 2 & 2131292 & 3,1144 & 25470 & 751 & 0,260261399 \\
\hline GEMİ 3 & 1409403 & 3,1144 & 24984,75 & 3712 & 0,035496688 \\
\hline GEMİ 4 & 3894765 & 3,1144 & 25362 & 694 & 0,516861154 \\
\hline GEMİ 5 & 2035327 & 3,1144 & 25239 & 980 & 0,192208048 \\
\hline GEMİ 6 & 3841482 & 3,1144 & 25362 & 1173 & 0,301615026 \\
\hline GEMİ 7 & 3908372 & 3,1144 & 24630,75 & 247 & 1,500572253 \\
\hline GEMİ 8 & 2259771 & 3,1144 & 25267,5 & 751 & 0,27816208 \\
\hline GEMİ 9 & 3805245 & 3,1144 & 18750 & 583 & 0,813108309 \\
\hline GEMİ 10 & 3908372 & 3,1144 & 24632,25 & 369 & 1,004386927 \\
\hline GEMİ 11 & 3307227 & 3,1144 & 153010,5 & 10236 & 0,004932285 \\
\hline GEMİ 12 & 5729280 & 3,1144 & 151038 & 9377 & 0,009448994 \\
\hline GEMİ 13 & 2291712 & 3,1144 & 146399,3 & 1639 & 0,022308886 \\
\hline GEMİ 14 & 10384320 & 3,1144 & 114456 & 12728 & 0,016650029 \\
\hline GEMİ 15 & 4573111 & 3,1144 & 113293,5 & 12760 & 0,007389104 \\
\hline GEMİ 16 & 2277389 & 3,1144 & 99402,75 & 4012 & 0,0133387 \\
\hline GEMİ 17 & 3384572 & 3,1144 & 87297 & 4012 & 0,022572475 \\
\hline GEMİ 18 & 2320358 & 3,1144 & 82368 & 208 & 0,31635075 \\
\hline GEMİ 19 & 1862016 & 3,1144 & 9801,75 & 999 & 0,444170747 \\
\hline GEMİ 20 & 2234419 & 3,1144 & 15750 & 4580 & 0,072352622 \\
\hline GEMİ 21 & 2315489 & 3,1144 & 33990 & 396 & 0,401820356 \\
\hline GEMİ 22 & 4654181 & 3,1144 & 33990 & 4673 & 0,068443458 \\
\hline GEMİ 23 & 5269649 & 3,1144 & 36000 & 946 & 0,361429557 \\
\hline GEMİ 24 & 5199608 & 3,1144 & 36720 & 2521 & 0,131199066 \\
\hline GEMİ 25 & 8192870 & 3,1144 & 35535 & 1605 & 0,335536973 \\
\hline GEMİ 26 & 5024722 & 3,1144 & 36000 & 1462 & 0,222996374 \\
\hline GEMİ 27 & 3164568 & 3,1144 & 15975 & 547 & 0,845905535 \\
\hline GEMİ 28 & 3219855 & 3,1144 & 15975 & 1476 & 0,318966294 \\
\hline GEMİ 29 & 2177126 & 3,1144 & 15337,5 & 55 & 6,028399609 \\
\hline GEMİ 30 & 2463590 & 3,1144 & 13530 & 1426 & 0,298254383 \\
\hline
\end{tabular}

Kaynak: Yazar Tarafindan Oluşturulmuştur. 
Gemi 1'den başlayarak bütün gemilerin EEOI hesaplamaları yapılmıştır. Araştırmada kullanılan gemilerden Ro-Ro kargo gemilerinin toplamda 5,127746 (g CO2/t.miles) 34\%, dökme yük gemilerinin 0,929515 (g CO2/t.miles) 6\% ve kargo gemilerinin 9,012952 (g CO2/t.miles) $60 \%$ oranında salınım yaptıkları görülmektedir. Gemilerin tam kapasiteyle çalışmaları durumunda hesaplamalar yapılmıştır. Gemilerin kapasite kullanım oranlarına göre çalışma durumları perspektifinde emisyon oranlarına ilişkin elde edilen bulgular Tablo3, 4 ve 5'te verilmiştir.

Tablo 3. Kapasitenin \%75 Olması Durumunda

\begin{tabular}{|c|c|c|c|c|c|}
\hline GEMİ & $\mathrm{FCJ}$ & CCARBON & MCARGO & DJ & GCO2/T.MİLES \\
\hline GEMİ 1 & 3256655,167 & 3,1144 & 25661,25 & 1750 & 0,225855312 \\
\hline GEMİ 2 & 1604019,36 & 3,1144 & 25470 & 751 & 0,261165084 \\
\hline GEMI 3 & 1060722,48 & 3,1144 & 24984,75 & 3712 & 0,03561994 \\
\hline GEMİ 4 & 2931216,024 & 3,1144 & 25362 & 694 & 0,518655811 \\
\hline GEMİ 5 & 1531795,37 & 3,1144 & 25239 & 980 & 0,192875437 \\
\hline GEMİ 6 & 2891115,54 & 3,1144 & 25362 & 1173 & 0,3026623 \\
\hline GEMI 7 & 2941456,739 & 3,1144 & 24630,75 & 247 & 1,505782573 \\
\hline GEMİ 8 & 1700713,269 & 3,1144 & 25267,5 & 751 & 0,27912792 \\
\hline GEMİ 9 & 2863842,899 & 3,1144 & 18750 & 583 & 0,815931602 \\
\hline GEMİ 10 & 2941456,739 & 3,1144 & 24632,25 & 369 & 1,007874382 \\
\hline GEMİ 11 & 2489032,73 & 3,1144 & 153010,5 & 10236 & 0,004949411 \\
\hline GEMI 12 & 4311880 & 3,1144 & 151038 & 9377 & 0,009481803 \\
\hline GEMİ 13 & 1724752 & 3,1144 & 146399,25 & 1639 & 0,022386348 \\
\hline GEMİ 14 & 7815282,5 & 3,1144 & 114456 & 12728 & 0,016707841 \\
\hline GEMİ 15 & 3441742,616 & 3,1144 & 113293,5 & 12760 & 0,00741476 \\
\hline GEMİ 16 & 1713972,3 & 3,1144 & 99402,75 & 4012 & 0,013385015 \\
\hline GEMI 17 & 2547243,11 & 3,1144 & 87297 & 4012 & 0,022650852 \\
\hline GEMİ 18 & 1746311,4 & 3,1144 & 82368 & 208 & 0,317449191 \\
\hline GEMİ 19 & 1401361 & 3,1144 & 9801,75 & 999 & 0,445713007 \\
\hline GEMİ 20 & 1681633,2 & 3,1144 & 15750 & 4580 & 0,072603846 \\
\hline GEMİ 21 & 1742646,302 & 3,1144 & 33990 & 396 & 0,403215566 \\
\hline GEMİ 22 & 3502755,718 & 3,1144 & 33990 & 4673 & 0,068681108 \\
\hline GEMİ 23 & 3965959,427 & 3,1144 & 36000 & 946 & 0,362684521 \\
\hline
\end{tabular}




\begin{tabular}{llllll} 
GEMI 24 & 3913246,694 & 3,1144 & 36720 & 2521 & 0,131654619 \\
GEMI 25 & 6165988,4 & 3,1144 & 35535 & 1605 & 0,336702032 \\
GEMI 26 & 3781626,557 & 3,1144 & 36000 & 1462 & 0,223770667 \\
GEMI 27 & 2381666,918 & 3,1144 & 15975 & 547 & 0,848842707 \\
GEMI 28 & 2423276,56 & 3,1144 & 15975 & 1476 & 0,320073816 \\
GEMI 29 & 1638514,4 & 3,1144 & 15337,5 & 55 & 6,049331552 \\
GEMİ 30 & 1854108,4 & 3,1144 & 13530 & 1426 & 0,299289989 \\
\hline
\end{tabular}

Kaynak: Yazar Tarafindan Oluşturulmuştur.

Tablo 3'te kapasitenin 75\% olması durumunda salg1lanan CO2 miktarı görülmektedir. Hesaplamalar kapasitenin tamamen dolu olduğu durumdaki yöntem ile yapılmıştır. Kapasitenin tamamen dolu olduğu durumda 30 geminin toplam 15,07021189 gCO2/t.miles karbon salınımı hesaplanmıştır. Gemi 75\% kapasite ile aynı seferi yaptığında ise 15,12253901 gCO2/t.miles karbon salınımı hesaplanmıştır.

Tablo 4. Kapasitenin \%50 Olması Durumunda

\begin{tabular}{|c|c|c|c|c|c|}
\hline GEMİ & FCJ & CCARBON & MCARGO & DJ & GCO2/T.MİLES \\
\hline GEMİ 1 & 2704489 & 3,1144 & 17107,5 & 1750 & 0,281342257 \\
\hline GEMİ 2 & 1332058 & 3,1144 & 16980 & 751 & 0,325326748 \\
\hline GEMİ 3 & 880876,8 & 3,1144 & 16656,5 & 3712 & 0,04437086 \\
\hline GEMİ 4 & 2434228 & 3,1144 & 16908 & 694 & 0,646076443 \\
\hline GEMİ 5 & 1272079 & 3,1144 & 16826 & 980 & 0,24026006 \\
\hline GEMİ 6 & 2400926 & 3,1144 & 16908 & 1173 & 0,377018782 \\
\hline GEMI 7 & 2442732 & 3,1144 & 16420,5 & 247 & 1,875715316 \\
\hline GEMİ 8 & 1412357 & 3,1144 & 16845 & 751 & 0,347702599 \\
\hline GEMİ 9 & 2378278 & 3,1144 & 12500 & 583 & 1,016385387 \\
\hline GEMİ 10 & 2442732 & 3,1144 & 16421,5 & 369 & 1,255483659 \\
\hline GEMİ 11 & 2067017 & 3,1144 & 102007 & 10236 & 0,006165356 \\
\hline GEMİ 12 & 3580800 & 3,1144 & 100692 & 9377 & 0,011811242 \\
\hline GEMİ 13 & 1432320 & 3,1144 & 97599,5 & 1639 & 0,027886108 \\
\hline GEMİ 14 & 6490200 & 3,1144 & 76304 & 12728 & 0,020812536 \\
\hline GEMİ 15 & 2858195 & 3,1144 & 75529 & 12760 & 0,00923638 \\
\hline GEMİ 16 & 1423368 & 3,1144 & 66268,5 & 4012 & 0,016673375 \\
\hline GEMİ 17 & 2115358 & 3,1144 & 58198 & 4012 & 0,028215594 \\
\hline GEMİ 18 & 1450224 & 3,1144 & 54912 & 208 & 0,395438438 \\
\hline
\end{tabular}




\begin{tabular}{llllll} 
GEMI 19 & 1163760 & 3,1144 & 6534,5 & 999 & 0,555213434 \\
GEMI 20 & 1396512 & 3,1144 & 10500 & 4580 & 0,090440777 \\
GEMI 21 & 1447180 & 3,1144 & 22660 & 396 & 0,502275445 \\
GEMI 22 & 2908863 & 3,1144 & 22660 & 4673 & 0,085554322 \\
GEMI 23 & 3293530 & 3,1144 & 24000 & 946 & 0,451786946 \\
GEMI 24 & 3249755 & 3,1144 & 24480 & 2521 & 0,163998833 \\
GEMI 25 & 5120544 & 3,1144 & 23690 & 1605 & 0,419421217 \\
GEMI 26 & 3140451 & 3,1144 & 24000 & 1462 & 0,278745468 \\
GEMI 27 & 1977855 & 3,1144 & 10650 & 547 & 1,057381919 \\
GEMI 28 & 2012410 & 3,1144 & 10650 & 1476 & 0,398707868 \\
GEMI 29 & 1360704 & 3,1144 & 10225 & 55 & 7,535499511 \\
GEMI 30 & 1539744 & 3,1144 & 9020 & 1426 & 0,372817979 \\
\hline
\end{tabular}

Kaynak: Yazar Tarafindan Oluşturulmuştur.

Tablo 4 'te geminin $50 \%$ doluluk oranına sahip olduğu haliyle hesaplama yapılmıştır. 50\% kapasiteyle 18,83776486 gCO2/t.miles CO2 salınımı görülmektedir.

Tablo 5. Kapasitenin \%50'nin Altında Olması Durumunda

\begin{tabular}{|c|c|c|c|c|c|}
\hline GEMİ & $\mathrm{FCJ}$ & CCARBON & MCARGO & DJ & GCO2/T.MİLES \\
\hline GEMİ 1 & 2197397 & 3,1144 & 11975,25 & 1750 & 0,326557977 \\
\hline GEMİ 2 & 1082297 & 3,1144 & 11886 & 751 & 0,377611404 \\
\hline GEMİ 3 & 715712,4 & 3,1144 & 11659,55 & 3712 & 0,051501891 \\
\hline GEMİ 4 & 1977810 & 3,1144 & 11835,6 & 694 & 0,749910157 \\
\hline GEMİ 5 & 1033564 & 3,1144 & 11778,2 & 980 & 0,278873284 \\
\hline GEMİ 6 & 1950753 & 3,1144 & 11835,6 & 1173 & 0,437611087 \\
\hline GEMİ 7 & 1984720 & 3,1144 & 11494,35 & 247 & 2,177169564 \\
\hline GEMİ 8 & 1147540 & 3,1144 & 11791,5 & 751 & 0,403583374 \\
\hline GEMİ 9 & 1932351 & 3,1144 & 8750 & 583 & 1,179733038 \\
\hline GEMİ 10 & 1984720 & 3,1144 & 11495,05 & 369 & 1,457257818 \\
\hline GEMİ 11 & 1679451 & 3,1144 & 71404,9 & 10236 & 0,007156217 \\
\hline GEMİ 12 & 2909400 & 3,1144 & 70484,4 & 9377 & 0,013709477 \\
\hline GEMİ 13 & 1163760 & 3,1144 & 68319,65 & 1639 & 0,032367804 \\
\hline GEMİ 14 & 5273288 & 3,1144 & 53412,8 & 12728 & 0,024157408 \\
\hline GEMİ 15 & 2322283 & 3,1144 & 52870,3 & 12760 & 0,010720798 \\
\hline GEMİ 16 & 1156487 & 3,1144 & 46387,95 & 4012 & 0,019353025 \\
\hline GEMİ 17 & 1718728 & 3,1144 & 40738,6 & 4012 & 0,032750243 \\
\hline GEMİ 18 & 1178307 & 3,1144 & 38438,4 & 208 & 0,458991044 \\
\hline GEMİ 19 & 945555 & 3,1144 & 4574,15 & 999 & 0,644444165 \\
\hline GEMİ 20 & 1134666 & 3,1144 & 7350 & 4580 & 0,104975902 \\
\hline
\end{tabular}




\begin{tabular}{llllll} 
GEMI 21 & 1175834 & 3,1144 & 15862 & 396 & 0,582998285 \\
GEMİ 22 & 2363451 & 3,1144 & 15862 & 4673 & 0,099304124 \\
GEMİ 23 & 2675993 & 3,1144 & 16800 & 946 & 0,524395563 \\
GEMİ 24 & 2640426 & 3,1144 & 17136 & 2521 & 0,190355788 \\
GEMİ 25 & 4160442 & 3,1144 & 16583 & 1605 & 0,486828198 \\
GEMİ 26 & 2551617 & 3,1144 & 16800 & 1462 & 0,323543846 \\
GEMİ 27 & 1607007 & 3,1144 & 7455 & 547 & 1,227318299 \\
GEMİ 28 & 1635083 & 3,1144 & 7455 & 1476 & 0,462785918 \\
GEMİ 29 & 1105572 & 3,1144 & 7157,5 & 55 & 8,746561933 \\
GEMI 30 & 1251042 & 3,1144 & 6314 & 1426 & 0,432735154 \\
\hline
\end{tabular}

Kaynak: Yazar Tarafindan Oluşturulmuştur.

Tablo 5. 50\%'nin altında olması durumunda salınan CO2 emisyonu hesaplanmıştır. Hesaplama sonucunda toplam 21,86526278 gCO2/t.miles salınım gerçekleştiği görülmektedir.

\section{Tartışma ve Değerlendirme}

Gemilerin doluluk oranlarına göre CO2 salınımları hesaplanmıştır. Gemilerin tam kapasiteyle çalıştıkları durumda 15,07021189 gCO2/t.miles salınım hesaplanırken 75\% kapasite ile 0,052327125 gCO2/t.miles, 50\% kapasite ile 3,767552972 gCO2/t.miles, 50\%'nin altındaki kapasite ile ise 6,795050896 gCO2/t.miles daha fazla salınım görülmektedir. Gemilerin kapasitelerinin altında yük taşıdığı durumlar hesaplanırken gemilerin FCi değerleri de düşürülmüştür. Geminin yük kapasitesinin düşürülmesi geminin daha az enerjiyle aynı rotada ve aynı yakıt türünü kullanarak seferini tamamladığı durum hesaplanmıştır. Araştırmanın kısıtlarından biri rassal olarak seçilen 30 gemi üzerinden yapılmasıdır. Bu 30 geminin sadece bir seferi seçilerek $\mathrm{CO} 2$ salınımı hesaplanmıştır. Seçilen gemiler ticari gemilerdir, diğer gemiler araştırmanın kapsamına alınmamıştır. Gemilerin yakıt türlerinden HFO değerlendirmeye alınmıştır, diğer 
gemi yakıtları hesaplanmamıştır. Gemiler stabilize için tam motor kapasitesi kullanımı tercih edebilmektedir. $\mathrm{Bu}$ araştırmada gemilerin motor kapasitelerinin düşük güçte çalıştırıldığ 1 durum hesaplanarak stabilizeleri hesaba katılmamıştır.

\section{Sonuç}

Denizyolu taşımacılığı diğer taşımacılık yöntemlerinin yanında taşımacılık başına çevreye daha az oranla zarar veriyor olsa dahi özellikle kullanım sıklığından dolayı bu oranlar geri dönülemez boyutlara ulaşmaktadır. Denizyolu taşımacılığı, iç suyolu taşımacılığ1 da ele alındığında su, hava ve limanlardan dolayı karayı da tehdit altına almaktadır. Biyolojik çeşitliliğin bozulması, su kirliliği, hava kirliliği, insan sağlı̆̆ının bozulması, küresel ısınma, sera etkisi gibi birçok çevresel etkiye neden olmaktadır. Bu etkilerin temel kaynağ ucuz ve ulaşılabilir olması sebebiyle fosil yakıtların tercih edilmesidir.

Denizyolu taşımacılığında emisyonların düşürülmesi, kirliliğin azaltılması için IMO'nun çeşitli denizyolu taşımacılığı yeşil çözümleri bulunmaktadır. Yeşil çözümler, geminin seyir hızının düşürülmesi, fosil yakıtların kullanımının azaltılması, daha temiz içerikli yeni nesil yakıt türlerinin tercih edilmesi, enerji verimliliğinin artması, hava durumuna bağlı seyir planının yapılması gibi çözümler öne sürmektedir. Çözümlerin matematiksel yöntemlerle uygulanabilirliğinin ve kontrolünün sağlanabilmesi için çeşitli hesaplama yöntemleri yayınlanmıştır. Bu yöntemler SEEMP, EEDI, EEXI, EEOI ve benzeri olarak sıralanabilmektedir. Araştırmalarda genellikle tercih edilen EEDI yönteminin temel amacı yeni gemiler üzerinde enerji verimliliği tasarım indeksi oluşturmaktır. EEOI 
yöntemi ise hali hazırda faaliyetlerine devam edilen gemilerin verimliliğini ölçmede kullanılmaktadır. Temel olarak aynı hesaplama olsa dahi EEDI ve EEOI arasındaki en büyük farklılık EEDI yönteminin yeni gemiler için kullanırken EEOI yönteminin faaliyetlerine devam eden gemiler için kullanılıyor olmasından kaynaklanmaktadır. Araştırmada 30 farklı geminin yapmış oldukları tek seferleri ele alınarak EEOI yöntemiyle hesaplamalar yapılmıştır. Gemilerin özelliklerinin birbirlerine yakın fakat temel olarak farklı olarak seçilmesine önem verilmiştir. Farklı olmasında temel amaç EEOI yönteminin uygulanabilirliğinin bütün gemiler üzerinde denenmesini sağlamaktır. EEOI yöntemi işletmelerde raporlama yöntemiyle kullanılarak 1 yıllık hedeflerin uygulanabilirliğinin ölçülmesinde kullanılmaktadır. Bu araştırmada gemilerin tek bir seferi seçilmiştir ve geminin EEOI değeri elde edilmiştir. Elde edilen değerin düşürülmesi için denizyolu taşımacılığında yeşil yöntemlerden yararlanılmıştır.

Gemilerin $\mathrm{CO} 2$ salınımlarının hesaplanmasında kullanılan EEOI yöntemi aracılığıyla gemi kapasitelerinin doluluk oranlarına göre hesaplamalar yapılmıştır. Bu doğrultuda yapılan hesaplamalar sonucunda gemilerde planlama süreçlerinin $\mathrm{CO} 2$ salınımı açısından önemi görülmüştür. Gemilerin stabilizesi düşünülmeden gemi motor kapasitelerinin de düşürüldüğü durumlarda dahi gemilerin aynı yakıt türü ve aynı rotada yaptıkları seferlerde daha fazla CO2 salınımı gerçekleştirdikleri görülmektedir. İşletmelerin maliyet açısından en yüksek faydayı sağlarken çevresel olarak en düşük zararın verilmesi için gemi yükleme planlamasının doğru şekilde yapılmasının önemi görülmüş̧ür. Gemi stabilizesi hesaplamalara eklendiği durumda geminin tam motor kapasitesinin tercihi söz konusu olabilmektedir. 
Geminin motor kapasitesinin tam olarak kullanılması ve yük kapasitesinin tam olarak kullanılmaması durumunda $\mathrm{CO} 2$ salınımı daha çok artmaktadır. Gemilerin CO2 salınımını düşürebilmesi ve işletmelerin maksimum verimle süreçlerine devam edebilmesi için planlama süreçlerinde iyileştirmelerin yapılmasının gerekliliği görülmüştür.

\section{Kaynakça}

Aksay, C. S., Ketenoğlu, O., \& Kurt, L. (2005). Küresel ısınma ve iklim değişikliği. S Ü Fen Ed Fak Fen Dergisi(25), 29-41.

Aygül, Ö., \& Baştuğ, S. (2020). Deniz taşımacılığı kaynaklı hava kirliliği ve insan sağllğına etkisi. Journal of Maritime Transport and Logistics, 1(1), 26-40.

Bozloğan, R. (2005). Sürdürülebilir gelişme düşüncesinin tarihsel arka planı. Sosyal Siyaset Konferansları Dergisi(50), 1011-1028.

Durmaz, M. (2015). Bir feribottan yayılan egzoz emisyonlarmın deneysel ve teorik olarak incelenmesi. İstanbul: İstanbul Teknik Üniversitesi Fen Bilimleri Enstitüsü, Yüksek Lisans Tezi.

European Commission. (2020). 2019 annual report on co2 emissions from maritime transport. Brussels: European Commission.

Eurostat Statics Explained. (2020, Ağustos). EuroStat. Eurostat Statics Explained: https://ec.europa.eu/ adresinden alındı

Internatıonal Marıtıme Organızatıon. (2009). Guidelines for voluntary use of the ship energy efficiency operational indicator (EEOI). London: IMO. 
Küçük, Y. K., \& Topçu, A. (2012). Deniz taşımacılığından kaynaklanan kirlilik. Ankara Üniversitesi Çevrebilimleri Dergisi, 4(2), 7579 .

Lister, J. (2014). Green shipping: governing sustainable maritime transport. Global Policy , 1-12.

Mitraa, S., Choudhury, B. K., Sengupta, P., \& Agrawal, K. M. (2019). Assessment of environmental sustainability of maritime sector. TERI Information Digest on Energy and Environment, 18(4), 397-414.

Özdağ, U. (2011). Sessiz Bahar'dan sonra ses getiren elli y1l: kadın, çevre, sağlık. Edebiyat Fakültesi Dergisi, 28(2), 179-199.

Özdemir, Ü. (2012). Türkiye'de gemilerden kaynaklı deniz kirliliğinin incelenmesi. Batman Üniversitesi Yaşam Bilimleri Dergisi, $1(2), 378-384$.

Psaraftis, H. N. (2016). Green maritime logistics: the quest for win-win solutions. Transport Research Arena Conference (s. 133-142). Warsaw: Elsevier.

Şenol, S. (2020). Gemi kökenli emisyonlara dayalı alternatif sevk sistemleri. GiDB Dergi(18), 31-56.

World Commission on Environment and Development (WCED). (1987). Ortak geleceğimiz (our common future). İngiltere: Oxford University Press. 